\title{
Induction of artificial cancer stem cells from tongue cancer cells by defined reprogramming factors
}

Koji Harada ${ }^{*}$, Tarannum Ferdous ${ }^{1}$, Dan Cui ${ }^{2}$, Yasuhiro Kuramitsu ${ }^{3}$, Takuya Matsumoto ${ }^{4}$, Eiji Ikeda ${ }^{2}$, Hideyuki Okano ${ }^{4}$ and Yoshiya Ueyama ${ }^{1}$

\begin{abstract}
Background: The cancer stem cells (CSCs), a small subpopulation of cells in tumor are responsible for the tumor initiation, growth, recurrence and metastasis of cancer, as well as resistance of cancers to drugs or radiotherapy. CSCs are an important target for the development of novel strategies in cancer treatment. However, CSCs-targeted new anti-cancer drug discovery is currently hindered by the lack of easy and reliable methods for isolating, collecting and maintaining sufficient number of CSCS. Here, we examined whether introduction of defined reprogramming factors (Oct4, shp53, Sox2, KIf4, I-Myc and Lin28) into HSC2 tongue cancer cells could transform the HSC2 into HSC2 with CSCs properties.
\end{abstract}

Methods: We introduced the defined reprogramming factors into HSC2 tongue cancer cells via episomal vectors by electroporation method to generate transfectant cells. We investigated the malignant properties of the transfectant cells by cell proliferation assay, migration assay, wound healing assay, sphere formation assay, chemosensitivity and radiosensitivity assay in vitro; and also examined the tumorigenic potential of the transfectants in vivo.

Results: The transfectant cells (HSC2/hOCT3/4-shp53-F, HSC2/hSK, HSC2/hUL, HSC2/hOCT3/4-shp53-F + hSK, HSC2/hOCT3/4-shp53-F + hUL, HSC2/hSK + hUL, HSC2/hOCT3/4-shp53-F + hSK + hUL) displayed a malignant phenotype in culture and form tumors on the back of nude mice more efficiently than parental HSC2 and control HSC2/EGFP transfectant cells. They exhibited increased resistance to chemotherapeutic agents; 5-fluorouracil, cisplatin, docetaxel, trifluorothymidine, zoledronic acid, cetuximab, bortezomib and radiation when compared with HSC2 and HSC2/EGFP. Among all the transfected cells, HSC2/hOCT3/4-shp53-F + hSK + hUL cell containing all of the reprogramming factors showed the most aggressive and malignant properties and presented the highest number of spheres in the culture medium containing human recombinant fibroblast Growth Factor-2 (FGF-2) and epidermal Growth Factor (EGF).

Conclusion: These findings suggest that artificial cancer stem cells obtained by the induction of cellular reprogramming may be useful for investigating the acquisition of potential malignancy as well as screening the CSCs-targeting drugs.

Keywords: Artificial CSC, Reprogramming factor, Episomal vector, Tongue cancer

\footnotetext{
* Correspondence: harako@yamaguchi-u.ac.jp

'Department of Oral and Maxillofacial Surgery, Yamaguchi University

Graduate School of Medicine, 1-1-1, Minamikogushi, Ube 755-8505, Japan

Full list of author information is available at the end of the article
} 


\section{Background}

Head and neck squamous cell carcinoma (HNSCC), including oral squamous cell carcinoma (OSCC) is a major health problem throughout the world. Despite advances in treatment of HNSCC, mortality from this disease remains high because of local and regional recurrences of tumors, acquired resistance of patients to chemotherapy or radiotherapy and high rate of metastases at the advanced stage of the disease [1]. Therefore, understanding the initial steps of the tumorigenic processes, as well as tumor progression and metastasis is required for the improvement of prognosis of OSCC and survival of the patients [2].

There are accumulating evidences that cancer cells are functionally heterogeneous and they go through proliferation, differentiation and maturation to a certain extent [3]. A solid tumor contains a distinct subpopulation of cells with stem cell properties (CSCs) that play important roles in cancer initiation, progression, recurrence and metastasis [4-7]. These CSCs are capable of longterm self-renewal and can generate phenotypically diverse tumor cell populations. In addition, they show resistance to radiation and chemotherapeutic agents [810]. Therefore, the development of new strategies for CSCs-targeted therapy has attracted attention in these years. Identification and characterization of CSC populations are important for the development of novel strategies for cancer treatment. Separation or generation of a sufficient number of CSCs from tumor tissues and amplification of the CSCs while stably maintaining them in an undifferentiated state in vitro is a pre-requisite to ensure a large-scale drug screening process [11]. CSCs could be identified and isolated through functional assays such as detection of the expression of the cell surface markers specific for CSCs or the sphere body formation method [12-14]. Until now, a number of CSC markers are identified in HNSCC, eg - CD44, CD44v4, CD44v6, ALDH1, CD166, and CD133 [15-19]. There are several other CSC markers reported in different cancer types, eg- CD34, CD133, CD90, CD13, EpCAM, ABCG, ALDH1 etc. [8]. Moreover, Side Population (SP) cells, which are a subpopulation of tumor cells with increased efflux capacity are also considered as a source of CSCs specially where CSC molecular markers are unknown [20, 21]. However, these methods that are dependent upon the isolation of CSCs from tumor tissues by flow cytometry or generation of spheres bodies have some real limitations [12-14]. Therefore, the isolation of sufficient number CSCs from tumor tissues is still difficult. Until now, an easy, cost-saving and optimal cell culture method for successfully amplifying and maintaining pure CSC populations is also unknown. Thus, screening of CSCs-targeting drugs in vitro and in animal models remain in a difficult situation. The development of an easy and efficient method to manufacture artificial CSCs is crucial to overcome these research obstacles.

It is believed that CSCs undergo differentiation into non-CSCs (cancer progeny cells), and that CSCs reach to the top of hierarchical system composed of cancer cells [22-25]. If non-CSCs can be dedifferentiated, CSCs may be generated artificially. Like normal pluripotent stem cells, CSCs are long-lived, and display quiescent potentials in a dormant state, and are responsible for angiogenic induction, apoptotic resistance and differentiation. CSC cells express stem cell marker genes, including Oct4, Sox2, Nanog, c-kit, ABCG2, and $A L D H$ [3, 26-28]. Among these genes, Oct4 is the key transcription factor that maintains the pluripotency and selfrenewal in undifferentiated embryonic stem cells [27]. Additionally, the essential role of $c-M y c$ and Klf4 in the regulation and maintenance of the stem cell-like features of tumor CSCs was reported by Wang et al. and $\mathrm{Yu}$ et al. respectively [29, 30].

The well-known work of generation of induced pluripotent stem cells (iPSCs) by Takahashi and Yamanaka showed that adult somatic cells can be reprogrammed to become pluripotent by the introduction of the pluripotent stem cell genes Oct4, Sox2, Klf4 and c-Myc [31, 32]. Additionally, Okita et al. mentioned the importance Lin 28 and $l$-myc for the generation of human iPSCs from blood cells $[33,34]$. The iPSCs development process shares many features with cancer development. Such similarities indicate that iPSCs reprogramming processes and carcinogenesis might be promoted by overlapping mechanisms; during which, somatic differentiated cell undergoes transcriptional changes and acquires self-renewal and unlimited proliferation capabilities [35-37]. Ohnishi et al. showed that, somatic cells that deviated successful reprogramming failed to develop iPSCs, but behaved similarly to cancer cells and developed Wilms tumor, a childhood blastoma in the kidney [38]. Thus, the same reprogramming factors that generate iPSCs could be also involved in carcinogenic transformation of normal somatic cells. Additionally, in neurosphere culture conditions, introduction of Oct4, Sox2, $c-M y c$ and Klf4 directly induced neural stem cells (NSCs) properties in somatic cells such as skin fibroblasts, which suggests that these reprogramming factors might possess the ability to induce stemness in somatic cells [39-42].

In this study, we followed the iPSCs-generation protocol obtained from the Center for iPS cell research and application (CiRA) website to reprogram HSC2 tongue cancer cells into CSCs [43]. We introduced $l-M y c$ instead of $c$ $M y c$ and two other factors (shp53 and Lin28) along with Oct4, Sox 2 and Klf4 into HSC2 cells via episomal vector; instead of using only Oct4, Sox2, Klf4 and $c-M y c$ with retroviral vectors as initially described by Takahashi and 
Yamanaka [31-33, 43]. The resultant cells possess the hallmarks of CSCs and could efficiently generate tumors in a nude mouse model. These results suggest that introduction of defined reprogramming factors can possibly dedifferentiate oral cancer cells into CSCs and can provide a potentially valuable system for the study of CSCs.

\section{Methods}

\section{Cell culture}

HSC2 cells were purchased from Cell Bank, RIKEN BioResource Center (Ibaraki, Japan). Cells were cultured in a 1:1 mixture of Dulbecco's modified Eagle's medium (D-MEM)/Ham's F-12 (Wako Pure Chemical Industries, Ltd. Osaka, Japan) supplemented with $10 \%$ fetal bovine serum (FBS) (Thermo Fisher scientific Inc., Waltham, MA, USA), $100 \mu \mathrm{g} / \mathrm{ml}$ streptomycin, 100 units $/ \mathrm{ml}$ penicillin (Thermo Fisher scientific) in a humidified atmosphere containing $5 \% \mathrm{CO}_{2}$ at $37{ }^{\circ} \mathrm{C}$. The electroporated cells, ie HSC2/EGFP, HSC2/hOCT3/4-shp53-F, HSC2/hSK, HSC2/ hUL, HSC2/hOCT3/4-shp53-F + hSK, HSC2/hOCT3/4shp53-F + hUL, HSC2/hSK + hUL, HSC2/hOCT3/4shp53-F + hSK + hUL were cultured in the same culture medium without any selection agents.

\section{Cell reprogramming and transfection}

Episomal vectors (pCXLE-hOCT3/4-shp53-F, pCXLEhSK, pCXLE-hUL and pCXLE-EGFP) were obtained from Addgene (Cambridge, MA, USA) and introduced into HSC2 cells in various combinations. An expression plasmid mixture containing one or more of these episomal vectors ( $1 \mu \mathrm{g}$ of each vector) were electroporated into $6 \times 10^{5}$ HSC2 cells with Neon Transfection System (Thermo Fisher scientific) using a $100 \mu \mathrm{l}$ kit according to the manufacturer's instructions (conditions for electroporation: pulse voltage: 1550 or $1650 \mathrm{~V}$, pulse width: $10 \mathrm{~ms}$, pulse number: 3 ). In the same way, we inserted pCXLE-EGFP only into HSC2 cells to obtain HSC2/ EGFP as a control. The list of expression plasmid mixtures used in the experiments and the resultant cells is shown in Table 1.

\section{Cell proliferation assay}

HSC2 or each transfectant $\left(5 \times 10^{3}\right.$ cells per well) were seeded on 96-well plates (Becton Dickinson Labware, Franklin lakes, NJ, USA) in D-MEM/Ham's F-12 medium supplemented with $10 \% \mathrm{FBS}$ and $1 \%$ penicillin/streptomycin. After 48 h or 72 h, 3-(4, 5-dimethylthiazol- 2-yl)-2, 5- diphenyltetrazolium bromide (MTT; Sigma-Aldrich, St. Louis, MO, USA) was added to each well ( $25 \mu \mathrm{l} /$ well) and incubated for $4 \mathrm{~h}$. Then dimethyl sulfoxide $(100 \mu \mathrm{l} /$ well $)$ was added to each well and a spectrophotometer (BioRad Laboratories, Hercules, CA, USA) was used to measure the absorbance at $490 \mathrm{~nm}$ (Optical Density 490 or OD490). All assays were run in triplicate.

Table 1 Summary of plasmid mixtures for electroporation

\begin{tabular}{|c|c|c|c|c|}
\hline Mix-ture & Plasmid name & Amount $(\mu \mathrm{g})$ & Genes & Resultant cell \\
\hline 1 & pCXLE-EGFP & 1 & Egfp & $\mathrm{HSC}$ /EGFP \\
\hline \multirow[t]{2}{*}{2} & pCXLE-hOCT3/4-shp53-F & 1 & Oct4, shp53, Egfp & HSC2/hOCT3/4-shp53-F \\
\hline & pCXLE-EGFP & 1 & & \\
\hline \multirow[t]{2}{*}{3} & pCXLE-hSK & 1 & Sox2, Klf4, Egfp & $\mathrm{HSC} 2 / \mathrm{hSK}$ \\
\hline & pCXLE-EGFP & 1 & & \\
\hline \multirow[t]{2}{*}{4} & pCXLE-hUL & 1 & I-Myc, Lin28, Egfp & $\mathrm{HSC} / \mathrm{hUL}$ \\
\hline & pCXLE-EGFP & 1 & & \\
\hline \multirow[t]{3}{*}{5} & pCXLE-hOCT3/4-shp53-F & 1 & Oct4, shp53,Sox2, KIf4, Egfp & HSC2/hOCT3/4-shp53-F + hSK \\
\hline & pCXLE-hSK & 1 & & \\
\hline & pCXLE-EGFP & 1 & & \\
\hline \multirow[t]{3}{*}{6} & pCXLE-hOCT3/4-shp53-F & 1 & Oct4, shp53, I-Myc, Lin28, Egfp & HSC2/hOCT3/4-shp53-F + hUL \\
\hline & pCXLE-hUL & 1 & & \\
\hline & pCXLE-EGFP & 1 & & \\
\hline \multirow[t]{3}{*}{7} & pCXLE-hSK & 1 & Sox2, KIf4, I-Myc, Lin28, Egfp & $\mathrm{HSC} 2 / \mathrm{hSK}+\mathrm{hUL}$ \\
\hline & pCXLE-hUL & 1 & & \\
\hline & pCXLE-EGFP & 1 & & \\
\hline \multirow[t]{4}{*}{8} & pCXLE-hOCT3/4-shp53-F & 1 & Oct4, shp53, Sox2, KIf4, I-Myc, Lin28, Egfp & HSC2/hOCT3/4-shp53-F + hSK + hUL \\
\hline & pCXLE-hSK & 1 & & \\
\hline & pCXLE-hUL & 1 & & \\
\hline & pCXLE-EGFP & 1 & & \\
\hline
\end{tabular}




\section{Cell migration assay}

Cell migration assay was performed using a Boyden chamber according to the manufacturer's instructions, (Neuro Probe, Gaithersburg, MD, USA). $5 \times 10^{3}$ cells in $50 \mu \mathrm{l}$ D-MEM/Ham's F-12 medium without FBS were seeded on a gelatin coated polycarbonate membrane. In the lower chamber, $25 \mu \mathrm{l}$ D-MEM/Ham's F-12 with $10 \%$ FBS was added as chemoattractant. After the cells were incubated for $24 \mathrm{~h}$ at $37{ }^{\circ} \mathrm{C}$ in a $5 \% \mathrm{CO}_{2}$ atmosphere, the polycarbonate membrane was washed with PBS, and cells on the top surface of the polycarbonate membrane were removed with a cotton swab. Cells adhering to the lower surface were fixed with methanol, stained with Hematoxylin solution and counted under a microscope in five predetermined fields (200x). All assays were independently repeated at least three times.

\section{Wound healing assay}

Cells $\left(15 \times 10^{3}\right.$ cells per well $)$ were seeded into 24 -well plate (Becton Dickinson Labware) and were cultured in D-MEM/Ham's F-12 with 10 \% FBS and 1 \% penicillin/ streptomycin until a monolayer of cells were formed. A $200 \mu \mathrm{l}$ pipette tip was used to gently wound cell layer through the central axis of the plate. The migration of cells into the wounded area was observed at $24 \mathrm{~h}$ by a microscope (BX-51-33-FLD2, OLYMPUS, PA, USA). The cell wound closure rate was calculated using the following equation: Wound closure $=[1-($ wound area at $\mathrm{Tt} /$ wound area at $\mathrm{T} 0) \times 100$, where $\mathrm{Tt}$ is the time passed since wounding $(24 \mathrm{~h})$ and $\mathrm{T} 0$ is the time of initial wounding. The experiments were performed in triplicate.

\section{Tumor sphere formation assay}

Cells were placed at a density of 1000 cells/well in sphere-culture medium consisting of serum-free DMEM/F-12 (Ham) 1:1 (Prototype) medium (Thermo Fisher scientific), N2 supplement (Thermo Fisher scientific), $10 \mathrm{ng} / \mathrm{ml}$ FGF-2 (Thermo Fisher scientific), and $10 \mathrm{ng} / \mathrm{ml}$ EGF (Thermo Fisher scientific) in a ultra-low attachment 96-well plate (Corning, New York, NY, USA) to generate primary sphere bodies. Every four days, $50 \mu \mathrm{L}$ of the fresh growth medium was added. The numbers of spheres larger than $20 \mu \mathrm{m}$ in diameter were counted after two weeks of culture.

\section{Western blotting}

Whole cell lysates were prepared using Radioimmunoprecipitation assay (RIPA) buffer (Thermo Fisher scientific) and were subjected to electrophoresis on $10 \%$ SDS-polyacrylamide gels (Thermo Fisher scientific), and then transferred to a PVDF membrane (Thermo Fisher scientific). After blocking, the membranes were incubated with the anti-HCAM (CD44) mouse monoclonal antibody (Santa Cruz Biotechnology, Inc., Santa Cruz,
CA, USA) and anti-CD13 rabbit monoclonal antibody (Epitomics Inc., Burlingame, CA, USA) followed by Novex $^{\odot}$ alkaline-phosphatase conjugated (goat) antirabbit or (goat) anti-mouse immunoglobulin G (IgG) secondary antibody (Thermo Fisher scientific). The antibodies were detected using a chromogenic immunodetection system, WesternBreeze (Thermo Fisher scientific) according to the manufacturer's instructions. Also, anti- $\alpha$ - tubulin monoclonal antibody (Santa Cruz Biotech.) was used for normalization of Western blot analysis.

\section{Chemosensitivity and radiosensitivity assessment}

Cells $\left(5 \times 10^{3}\right.$ cells per well) were seeded on 96-well plates (Becton Dickinson Labware) in D-MEM/Ham's F12 with $10 \% \mathrm{FBS}$ and $1 \%$ penicillin/streptomycin. Twenty four hours later, cells were either remained untreated or were treated with any one of the following drugs: $2 \mu \mathrm{g} / \mathrm{ml}$ 5-fluorouracil (5-FU), $1 \mu \mathrm{g} / \mathrm{ml}$ cisplatin (CDDP), $100 \mathrm{pg} / \mathrm{ml}$ docetaxel (DOC), $50 \mu \mathrm{g} / \mathrm{ml}$ trifluorothymidine (TFT), $1 \mu \mathrm{g} / \mathrm{ml}$ cetuximab, $5 \mathrm{ng} / \mathrm{ml}$ bortezomib or $10 \mu \mathrm{g} / \mathrm{ml}$ zoledronic acid. Cells were also exposed to 15 Gy radiation in an X-ray irradiator (MBR1505R2, $150 \mathrm{kV}, 5 \mathrm{~mA}$, filter: $1.0 \mathrm{~mm}$ aluminum, Hitachi Medico, Tokyo, Japan). After $48 \mathrm{~h}, 25 \mu \mathrm{l}$ MTT was added to each well. After $4 \mathrm{~h}$, dimethyl sulfoxide $(100 \mu \mathrm{l} /$ well $)$ was added and the absorbance was measured with a spectrophotometer (BioRad Laboratories) at $490 \mathrm{~nm}$. All assays were run in triplicate.

\section{In vivo tumor formation assay}

Cells $\left(1 \times 10^{4} \sim 1 \times 10^{6}\right)$ were washed twice with antibiotic-free and serum-free D-MEM/Ham's F-12 medium and finally re-suspended in $0.1 \mathrm{ml}$ of saline. The cell suspension was injected subcutaneously into 5week-old BALB/c nude mice (CLEA, Tokyo Japan). Tumor size was monitored and measured weekly for 4 weeks. The estimated tumor volume was calculated as $0.5 \times$ length $\times$ width $^{2}$. All mice were sacrificed at the end of 4 weeks/28 days. The tumors were dissected out, fixed in neutral-buffered formalin, embedded in paraffin and stained with hematoxylin and eosin. The mice were housed in a pathogen-free environment under a $12 \mathrm{~h}$ light/dark cycle, and provided with sterile water and food ad libitum. All studies and experiments conformed to the Guidelines for Animal Experimentation of Yamaguchi University (Ube, Japan).

\section{Results}

Establishment of transfectants by defined reprogramming factors

We successfully introduced the reprogramming factors (Oct4, shp53, Sox2, Klf4, l-Myc and Lin28) and Egfp genes via the plasmid vectors (pCXLE-hOCT3/4-shp53-F, 
pCXLE-hSK, pCXLE-hUL and pCXLE-EGFP) into HSC2 cells by electroporation in order to obtain HSC2/EGFP, HSC2/hOCT3/4-shp53-F, HSC2/hSK, HSC2/hUL, HSC2/ hOCT3/4-shp53-F + hSK, HSC2/hOCT3/4-shp53-F + hUL, HSC2/hSK + hUL and HSC2/hOCT3/4-shp53-F + hSK + hUL cells. Fluorescence microscopic observation of EGFP expression in transfectant cells showed the vector transplantation efficiency was about $50 \%$ when the pulse voltage of the electroporator was $1650 \mathrm{~V}$, and that about $30 \%$ at $1550 \mathrm{~V}$ (data not shown). Therefore, the optimum condition for electroporation was set as; pulse voltage: $1650 \mathrm{~V}$, pulse width: $10 \mathrm{~ms}$, pulse number: 3 . The transfectants were cultured in D-MEM/Ham's F-12 medium supplemented with $10 \% \mathrm{FBS}, 1 \%$ penicillin/streptomycin. In this study, we did not use any selection methods to identify stable transfectants. The transfected cells were bigger and spindle-shaped compared to $\mathrm{HSC} 2$ parental cells which had cobblestone morphology (Fig. 1) Moreover, each transfectant cells showed slightly different morphology than the other (Fig. 1).

\section{Cell proliferation ability}

MTT assay was used to measure the growth rate of the transfectants. The HSC2/hOCT3/4-shp53-F + hSK + hUL had higher proliferative ability than that of parental cell (HSC2) and HSC2/EGFP. At $48 \mathrm{~h}$ and $72 \mathrm{~h}$ of culture, the growth rate of HSC2/hOCT3/4-shp53-F + hSK + hUL was significantly higher than that of $\mathrm{HSC} 2$ and HSC2/EGFP, while the growth rate among parental
HSC2 cell, HSC2/EGFP and the other transfectants was not significantly different (Fig. 2).

\section{Migration ability}

CSCs are endowed with high migratory ability. Therefore, we measured the migration activity of the transfectants using migration assay with Boyden chamber. The HSC2/hOCT3/4-shp53-F + hSK, $\quad$ HSC2/hOCT3/4shp53-F + hUL, HSC2/hSK + hUL and HSC2/hOCT3/4shp53-F + hSK + hUL had significantly higher migration ability than that of parental cell (HSC2) and HSC2/ EGFP. Especially, the HSC2/hOCT3/4-shp53-F + hSK + hUL showed highest migration ability (Fig. 3).

\section{Wound healing ability}

Wound healing assay was performed to examine the migration capability of the transfectants. HSC2/hOCT3/4shp53-F + hSK + hUL cell showed highest would healing capacity (wound closure: $85 \%$ ) compared to HSC2/ EGFP (60\%), all the other transfectants (50-80\%) and the parental HSC2 cell (35\%). Interestingly, all the transfectant cells showed higher wound healing ability than that of parental HSC2 (Fig. 4a, b). HSC2/hUL + hSK cells showed second highest migration and wound healing capacity ( $80 \%$ ) which suggests that Sox2, Klf4, l$M y c, \operatorname{Lin} 28$ factors are essential to increase the migration capacity of the transfectants.

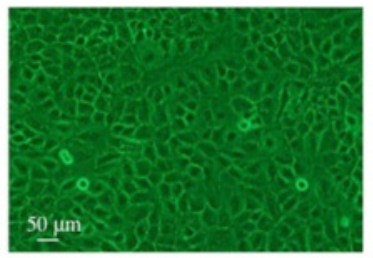

HSC2 parental

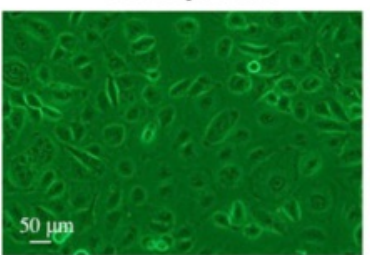

$\mathrm{HSC} 2 / \mathrm{hSK}$

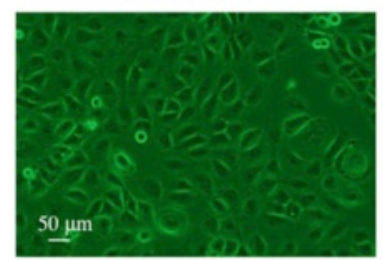

HSC2/hOCT3/4-shp53-F+hUL

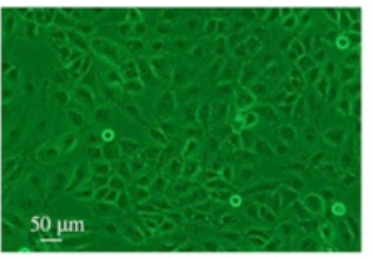

HSC2/EGFP

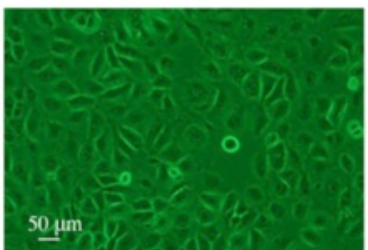

$\mathrm{HSC} 2 / \mathrm{hUL}$

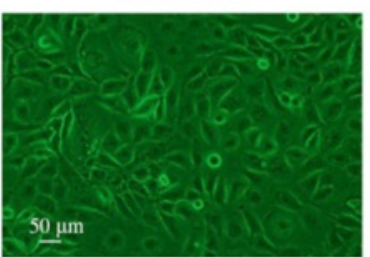

$\mathrm{HSC} 2 / \mathrm{hSK}+\mathrm{hUL}$

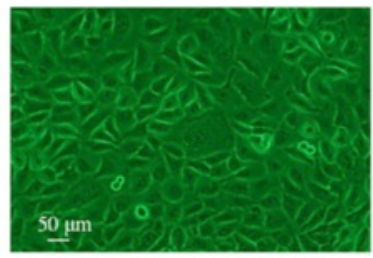

HSC2/hOCT3/4-shp53-F

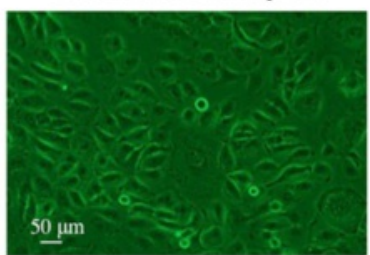

HSC2/hOCT3/4-shp53-F+hSK

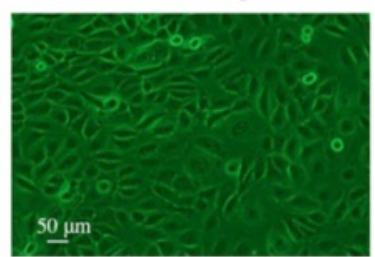

HSC2/hOCT3/4-shp53-F+hSK+hUL

Fig. 1 Cell morphology. All transfectants are morphologically distinct from their parental cell line (HSC2) and from each other. All transfectants have shown the loss of cell-cell adhesion (except HSC2/EGFP) and showed spindle-shaped morphology 


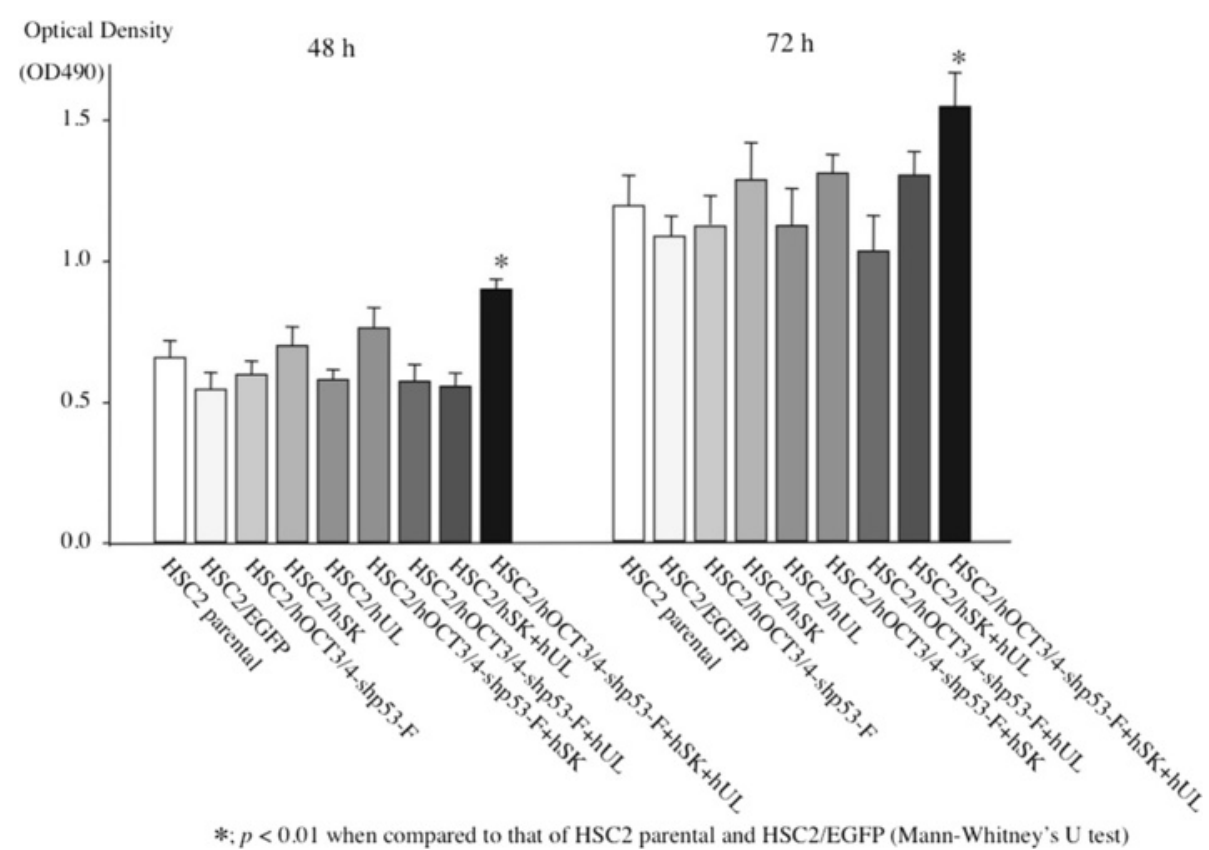

Fig. 2 Cell proliferation assay. Cells $\left(5 \times 10^{3}\right.$ cells per well) were seeded on $96-$ well plates, and cultured for 48 and 72 h. Cell growth was evaluated by MTT assay (OD490; absorbance at $490 \mathrm{~nm}$ ). The growth rate of HSC2/hOCT3/4-shp53-F + hSK + hUL was significantly higher than that of HSC2 and $\mathrm{HSC2} / \mathrm{EGFP}$ at 48 and $72 \mathrm{~h}$ after seeding. Error bars represent the standard deviation of the mean of three independent experiments

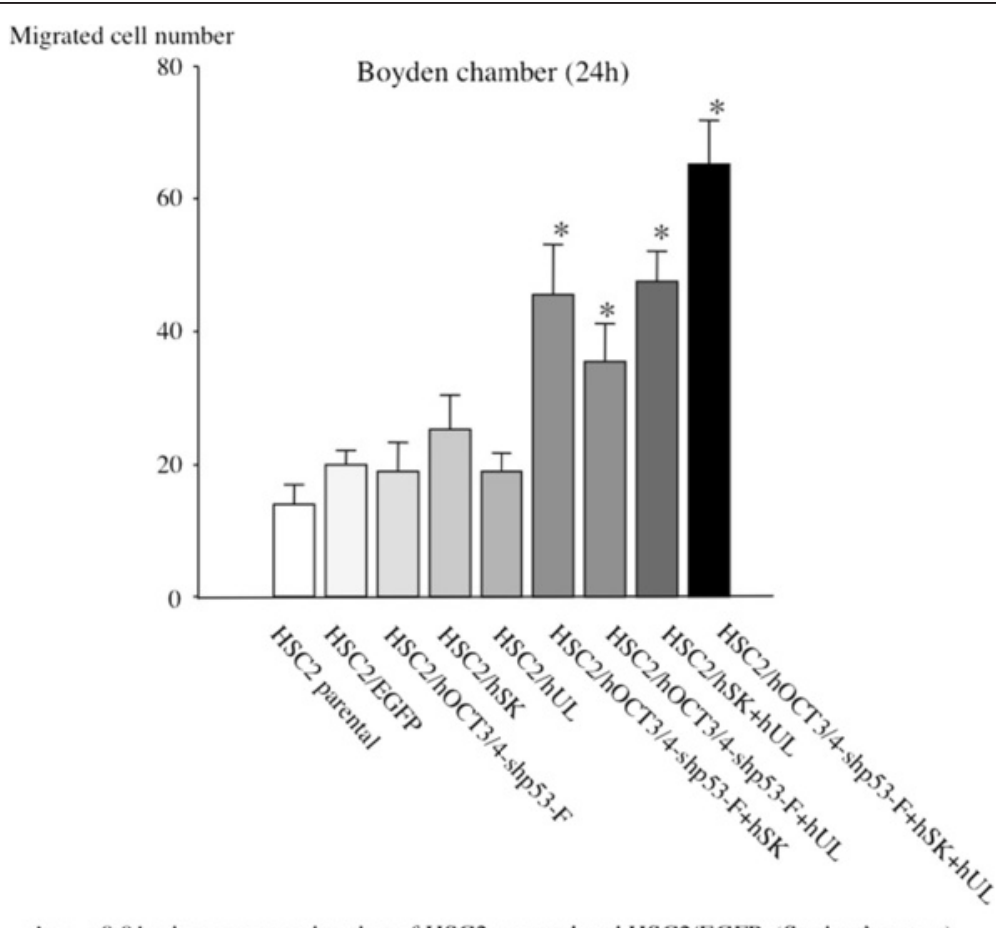

$*: p<0.01$ when compared to that of HSC2 parental and HSC2/EGFP (Student's t- test)

Fig. 3 Migration assay. To evaluate the migration activity for the transfectants, migration assay was performed with Boyden chamber. The HSC2/ hOCT3/4-shp53-F + hSK + hUL showed highest migration ability. Error bars represent the standard deviation of the mean of three independent experiments 
a

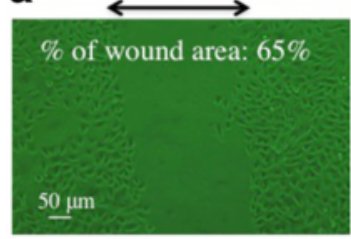

HSC2 parental

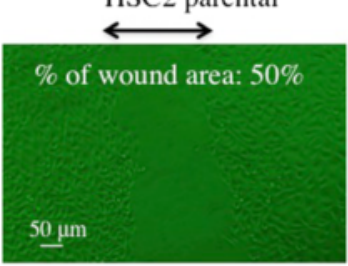

$\mathrm{HSC} 2 / \mathrm{hSK}$

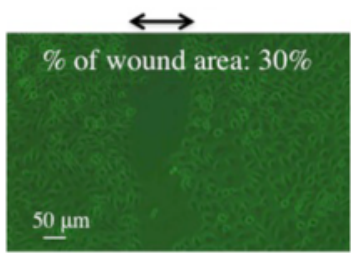

HSC2/hOCT3/4-shp53-F+hUL



HSC2/EGFP

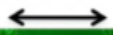

$\%$ of wound area: $45 \%$

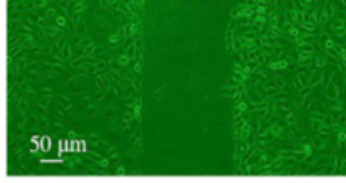

$\mathrm{HSC} 2 / \mathrm{hUL}$

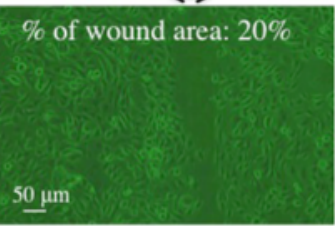

$\mathrm{HSC} 2 / \mathrm{hSK}+\mathrm{hUL}$

(24h after scratch)

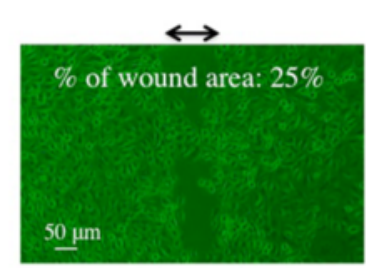

HSC2/hOCT3/4-shp53-F

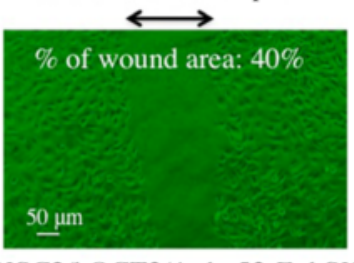

HSC2/hOCT3/4-shp53-F+hSK

$\%$ of wound area: $15 \%$

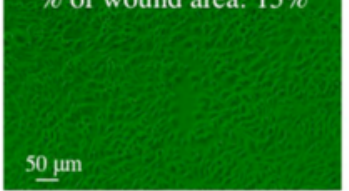

HSC2/hOCT3/4-shp53-F+hSK+hUL

b Wound closure

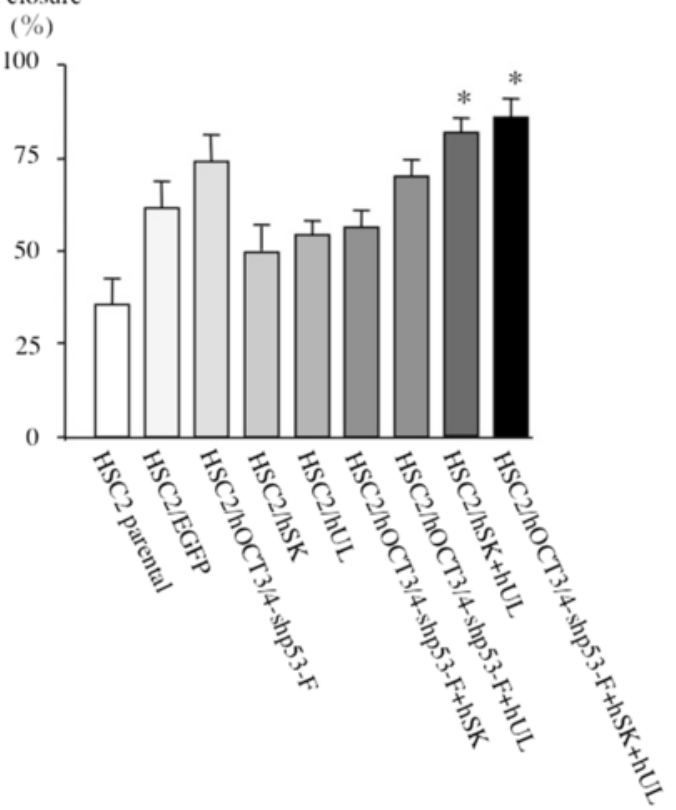

$* ; p<0.01$ when compared to that of HSC2 parental and HSC2/EGFP (Mann-Whitney's U test)

Fig. 4 Wound healing assay. The wound healing ability for the transfectants was measured by wound healing assay. A. The HSC2/hOCT3/4shp53-F + hSK + hUL had higher wound healing ability than that of HSC2 and HSC2/EGFP. Arrows show the width of uncovered scratch mark. The wound area was calculated according to the following formula: (wound area at Tt/wound area at T0) $\times 100$, where Tt is the time passed since wounding and TO is the time of initial wounding. B. The wound healing capacity for each cell type was calculated using the following equation: Wound closure $=[1-($ wound area at Tt/wound area at T0) $\times 100$. Error bars represent the standard deviation of the mean of three independent experiments 
a Number of Sphere

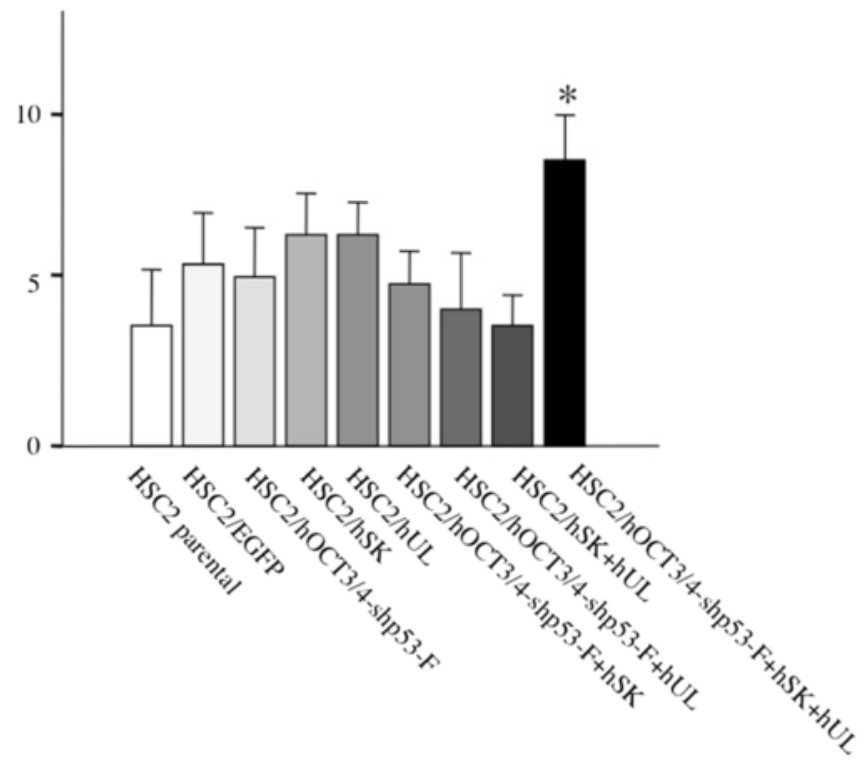

$*: p<0.01$ when compared to that of HSC2 parental and HSC2/EGFP (Student's t- test)

b

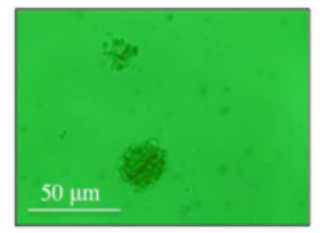

HSC2 parental

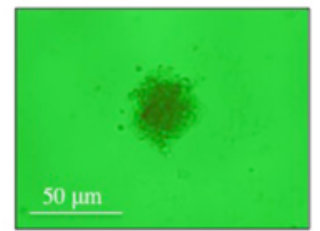

$\mathrm{HSC} 2 / \mathrm{hSK}$

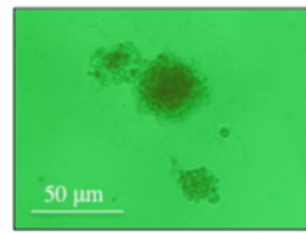

HSC2/hOCT3/4-shp53-F+hUL

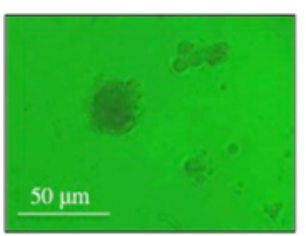

HSC2/EGFP

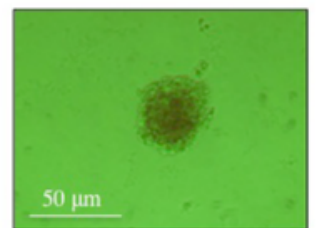

HSC $2 / h U L$

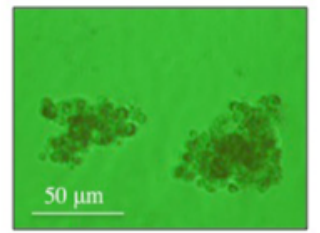

$\mathrm{HSC} 2 / \mathrm{hSK}+\mathrm{hUL}$

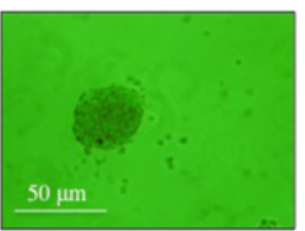

HSC2/hOCT3/4-shp53-F

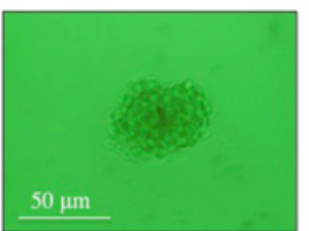

HSC2/hOCT3/4-shp53-F+hSK

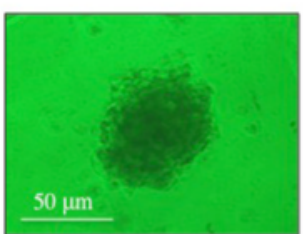

HSC2/hOCT3/4-shp53-F+hSK+hUL

( 2 weeks from culture)

Fig. 5 Sphere formation assay. The transfectants and HSC2 cells were cultured in a sphere-culture medium. a The number of spheres was significantly higher in the HSC2/hOCT3/4-shp53-F + hSK + hUL than HSC2 and HSC2/EGFP. Error bars represent the standard deviation of the mean of three independent experiments. $\mathbf{b}$ Representative images of sphere $(\mathrm{s})$ generated from each cell types $(\mathrm{Bar}=50 \mu \mathrm{m})$. The HSC2/hOCT3/4-shp53-F + hSK + hUL could also form bigger spheres 


\section{Sphere formation}

The transfectants, HSC2/EGFP and HSC2 cells were cultured in tumor sphere-culture medium. All cells were able to grow and form primary spheres within 2 weeks of culture; however, the HSC2/hOCT3/4-shp53-F + hSK + hUL cells could form spheres burly and numerously. Briefly, the number of spheres was significantly higher in the HSC2/hOCT3/4-shp53-F + hSK + hUL cell than HSC2 and HSC2/EGFP cell (Fig. 5a). HSC2/hOCT3/4shp53-F + hSK + hUL cells also developed comparatively bigger spheres than other cell types (Fig. 5b).

\section{Expression of CSC markers}

The expression pattern of CSC markers (CD44 and CD13) in the transfectants and HSC2 cells was analyzed by Western blotting. The protein expression of CD44 was significantly higher in $\mathrm{HSC} 2 / \mathrm{hOCT} 3 / 4-$ shp53-F + hSK + hUL than in HSC2/EGFP and HSC2, whereas CD13 expression was higher in all transfectant cells compared to HSC2 parental cell (Fig. 6).

\section{Chemosensitivity and radiosensitivity (in vitro)}

CSCs show resistance to anticancer drugs and radiation. Therefore, we evaluated the resistance ability of the transfectants to several chemotherapeutic drugs and radiation. The HSC2/hOCT3/4-shp53-F + hSK + hUL cell showed increased resistance to 5-FU, CDDP, DOC, TFT, zoledronic acid, cetuximab, bortezomib and $\mathrm{X}$-ray radiation than other transfectants and HSC2 cells (Fig. 7).

\section{Tumorigenesis (in vivo)}

The tumorigenic capacity of the transfectants was assessed using a mouse model. We injected each transfectant, HSC2 or HSC2/EGFP subcutaneously into $\mathrm{BALB} / \mathrm{c}$ nude mice and monitored them for 4 weeks.
While $1 \times 10^{4}$ cells of HSC2/hOCT3/4-shp53-F + hSK + hUL were enough to generate tumor in mice within 2 weeks, the same number of cells did not produce any HSC2 or HSC2/EGFP tumors. The minimum number of cells required for generating $\mathrm{HSC} 2$ or $\mathrm{HSC} 2 / \mathrm{EGFP}$ tumor in mice was $1 \times 10^{6}$ (data not shown), which was 100-fold higher than the number of HSC2/hOCT3/4shp53-F + hSK + hUL required for tumor seeding. In addition, HSC2/hOCT3/4-shp53-F + hSK + hUL showed higher tumorigenic potential (Fig. 8a-c). Histological analysis of these tumors showed squamous cell carcinoma tissues including from highly to poorly differentiated areas, but teratomas were not observed (Fig. 9).

\section{Discussion}

In this study, we demonstrated that the introduction of defined reprogramming factors (Oct4, shp53, Sox2, Klf4, $l-M y c$ and Lin28) could generate cells with CSC-like properties from a tongue cancer cell line, HSC2. These artificial CSCs showed resistance to anticancer drugs, molecular target drugs and radiation. Moreover, these artificial CSCs could be maintained in a cost-effective way. D-MEM medium supplemented with $10 \%$ FBS was sufficient to maintain these cells with CSC properties. These artificial CSCs could be handled easily and also managed to produce spheres in sphere-culture medium. Therefore, we may be able to develop a new strategy for generating and maintaining artificial CSCs.

We used HSC2 cell line in our present study, as it has neither invasive nor metastatic potential and showed low expression of the stem cell markers, ie- CD44 and CD13 (Fig. 6). In this study we also examined the expression of CD44v6, ALDH1, CD133 and podoplanin/ D2-40, but their expression patterns in transfectant cells were not different compared to that of $\mathrm{HSC} 2$ parental

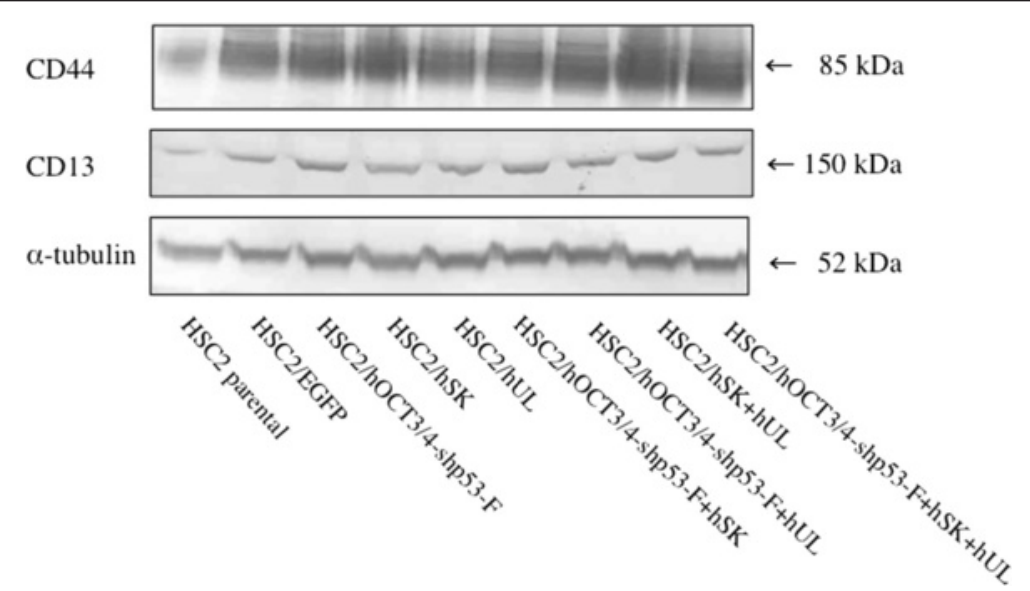

Fig. 6 Expression of CSC markers. Western blotting was performed to investigate protein levels of CSC markers (CD44 and CD13). CD44 expression was significantly higher in HSC2/hOCT3/4-shp53-F + hSK + hUL than other transfectants and HSC2. CD13 expression was higher in all other transfectant cells than HSC2/EGFP and parental HSC2. a-tubulin was used as an internal control 


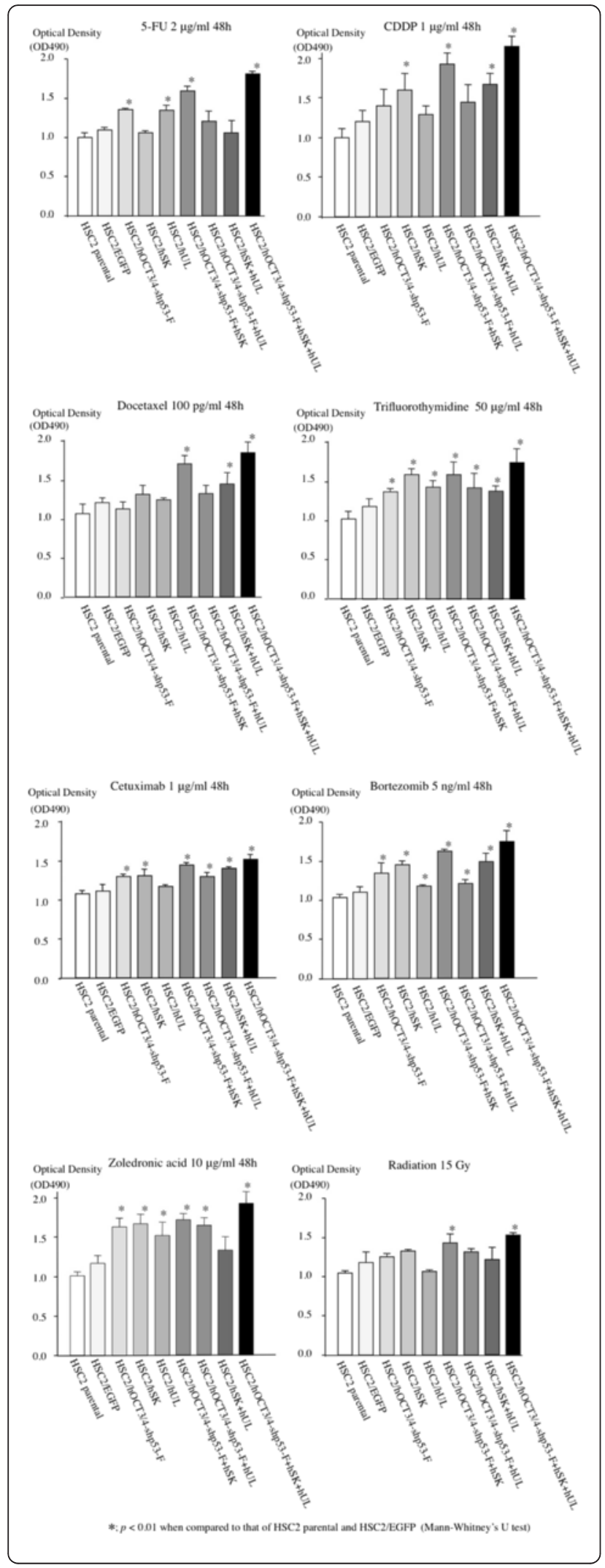

Fig. 7 Chemosensitivity and radiosensitivity assay. To evaluate the resistance of the transfectants to various chemotherapeutic drugs, molecular-targeted agents, and radiation, MTT assay was performed (OD490; absorbance at $490 \mathrm{~nm}$ ). The HSC2/hOCT3/4-shp53-F + hSK + hUL was significantly more resistant to 5-FU, CDDP, DOC, TFT, zoledronic acid, cetuximab, bortezomib and $\mathrm{X}$-ray radiation than HSC2 and HSC2/EGFP. Error bars represent the standard deviation of the mean of three independent experiments

cells (data not shown). After introduction of the reprogramming factors, most of the transfectants showed higher invasion and migration ability than $\mathrm{HSC} 2$ or HSC2/EGFP. Interestingly, HSC2/hOCT3/4-shp53-F + hSK + hUL cell containing all the reprogramming factors had acquired highest malignant properties in migration assay (Fig. 3), wound healing assay (Fig. 4) and sphere formation assay (Fig. 5) compared to the other transfectants, while demonstrating high expression of CD44. Moreover, our in vivo study showed that tumors developed from HSC2/hOCT3/4-shp53-F + hSK + hUL cells containing all the reprogramming factors (Oct3/4, shp53, Sox2, Klf4, l-Myc or Lin28) exhibited higher tumorigenic potential than parental HSC2 cells. Additionally, these tumors were not teratomas which suggest that our transfectant cells are not iPSCs.

CSCs may be derived from tissue stem cell, however, most of CSCs may be generated from non-tumorigenic differentiated epithelial cells by reprogramming. Nishi et al. reported that the introduction of defined reprogramming factors (Oct4, Sox2, Klf4 and c-Myc) into MCF10A nontumorigenic mammary epithelial cells, followed by partial differentiation, transforms the bulk of cells into tumorigenic cells with CSC properties [44]. Miyoshi et al. reported that introduction of defined reprogramming factors (Oct4, Sox2, Klf4 and c-Myc) into human gastrointestinal cancer cell lines resulted improved sensitivity of the induced cells to chemotherapeutic agents and differentiation-inducing treatment [45]. Moreover, Oshima et al. reported the generation of CSCs with lineage specificity directly from colon cancer cells by introducing same defined factors (except $c-M y c$ ), not via an induced pluripotent stem cell state [46].

There are many attempts to generate iPSCs from malignant tumor cells by the ectopic expression of reprogramming factors. Carette et al. reported to generate the iPS cells derived from human chronic myeloid leukemia cells by using the reprogramming factors (Oct4, Sox2, Klf4 and $c-M y c$ ) [47]. Similarly, Utikal et al. reported that they attempted to create iPSCs from melanoma by using the reprogramming factors [48]. However, it seems to achieve only limited success. It may be selected whether the ectopic expression of reprogramming factors in malignant tumor cell lines can induce cells with CSC-like properties or iPSCs during the reprogramming step. 
a

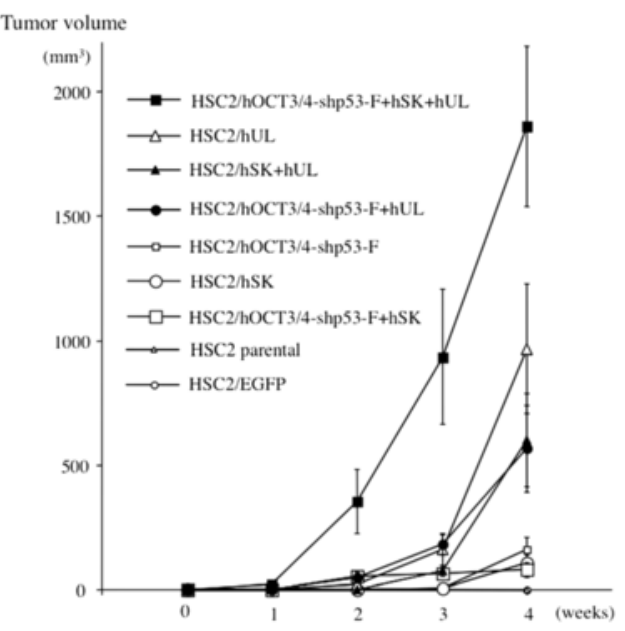

b
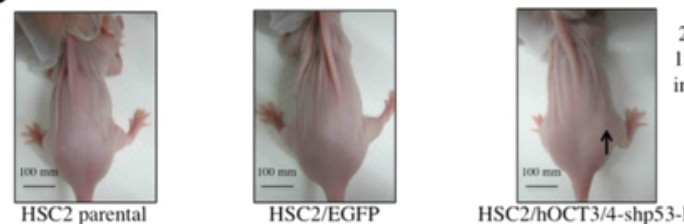

2 weeks after $1 \times 10^{4}$ cells injection
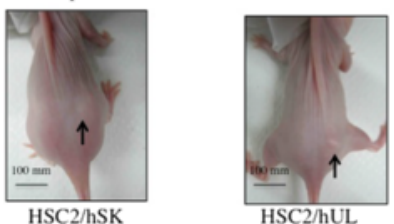

HSC2/hOCT3/4-shp $53-\mathrm{F}$

$\mathrm{HSC} 2 / \mathrm{hSK}$
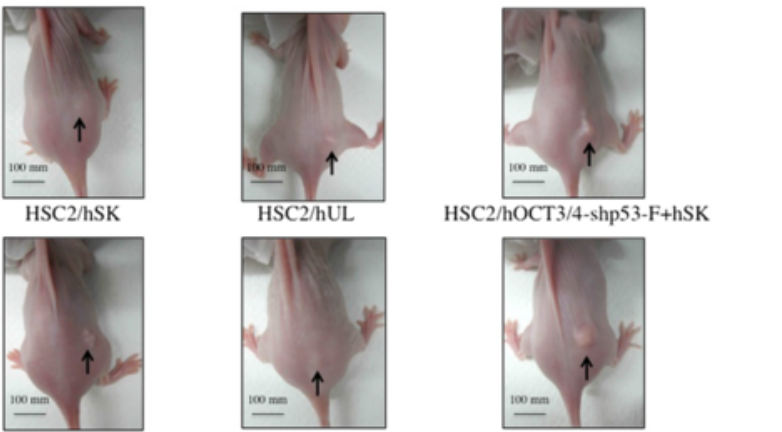

$\mathrm{HSC} 2 / \mathrm{hSK}+\mathrm{hUL}$

HSC2/hOCT3/4-shp53-F+hSK

HSC2/hOCT3/4-shp53-F+hUL

c
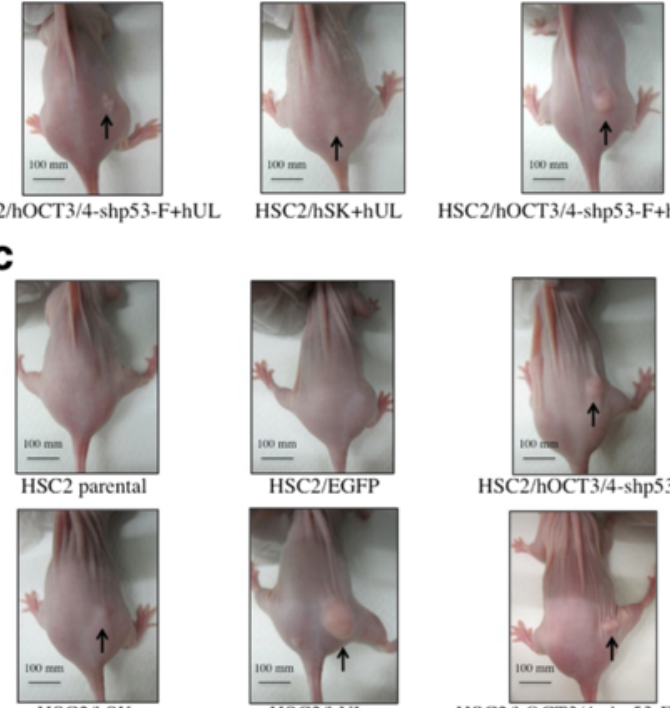

HSC2/hOCT3/4-shp53-F+hSK+hUL
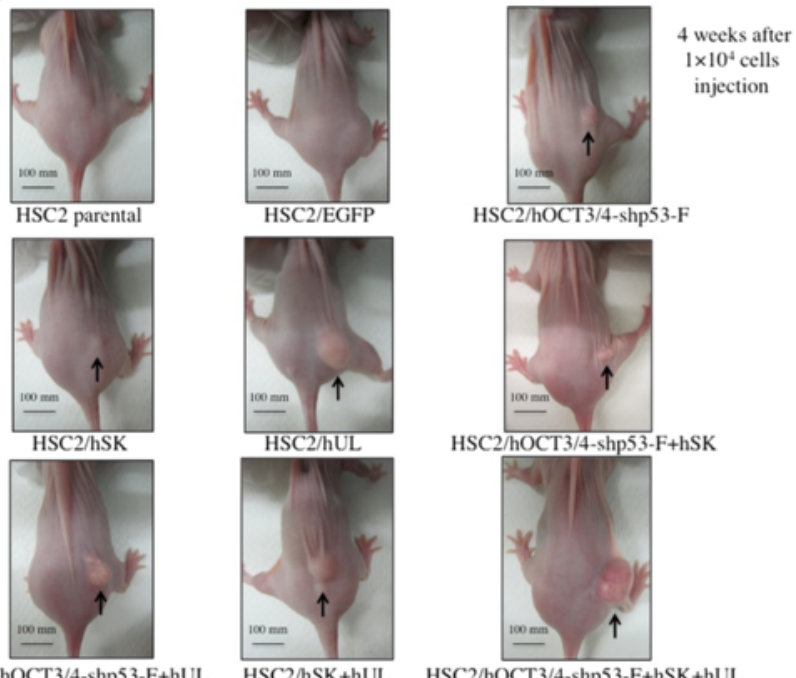

HSC2/hOCT3/4-shp53-F+hUL

HSC $2 / \mathrm{hSK}+\mathrm{hUL}$

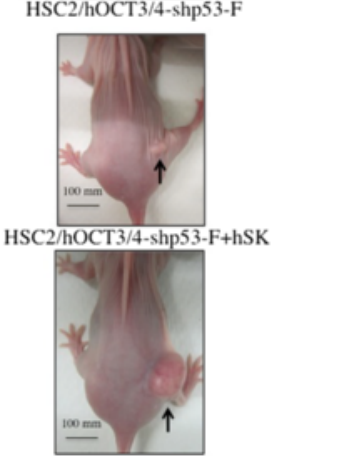

Fig. 8 (See legend on next page.) 
(See figure on previous page.)

Fig. 8 In vivo tumor formation assay. Each transfectant, HSC2 or HSC2/EGFP $\left(1 \times 10^{4}\right)$ were inoculated into BALB/c nude mice subcutaneously and tumor volume was measured once a week for 4 weeks. a Change of tumor volume. Error bars represent the standard error of the mean from three mice results $(n=3)$. b Nude mice tumor at 2 weeks after $1 \times 10^{4}$ cells injection. c Nude mice tumor at 4 weeks after $1 \times 10^{4}$ cells injection $(\mathrm{Bar}=10 \mathrm{~mm})$. Arrows show the tumor mass

CSCs are known to have high proliferation potency in some cancer types (eg - leukemia), whereas other reports describes CSCs as a slowly dividing cell population (egmelanoma) and it has also been suggested that as CSCs divide slowly, the CSC population is responsible for tumor resistance to treatment [49]. However, our HSC2/ hOCT3/4-shp53-F + hSK + hUL cell had higher proliferative activity though it showed resistance to various chemotherapeutic drugs, molecular-targeted agents, and radiation (Figs. 2 and 7). It is the general idea that, higher proliferation potency may lead to higher intake of anticancer agents inside the cancer cell. One proposed model that explains the origin of CSC's ability to survive conventional chemotherapeutic regimens describes that, only the CSCs overexpressing ATP-binding cassette $(\mathrm{ABC})$ transporters are able to repopulate the tumor after exposure to the chemotherapeutic agents [50]. The multidrug efflux pump ABCG2 has roles in cytotoxic drug efflux and has been described as one of the reason of the "side population" which helps define adult stem cells of tumors [51]. So, we examined the expression of
ABCG2 between the transfectants and HSC2/EGFP or $\mathrm{HSC} 2$ to investigate the reason why the HSC2/hOCT3/ 4-shp53-F + hSK + hUL showed resistance to various chemotherapeutic drugs in spite of its higher proliferation potency. However, we could not detect any differences of ABCG2 expression between the transfectants and HSC2/EGFP or HSC2 (data not shown).

The CSC markers differ in different cancer types. Until now, a number of markers have been discovered, ie - CD44, CD44v4, CD44v6, CD34, CD133, CD166, CD90, CD13, EpCAM, ABCG2, ALDH1 etc. $[8, a, b, c]$. However, in this present study we reported the expression pattern of only a few. Further experimentation is necessary to understand the expression of other CSC markers in $\mathrm{HSC} 2$ and in the transfectants. The reprogramming factors (Oct4, Sox2, Klf4, l$M y c$ or Lin28) we used in this study might be a few of the key molecules that can trigger the conversion of non-CSCs into CSC in oral tumors. Therefore, it is necessary to identify the other key molecules that are required for the development of CSCs.

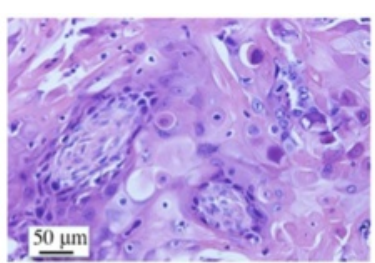

HSC2 parental

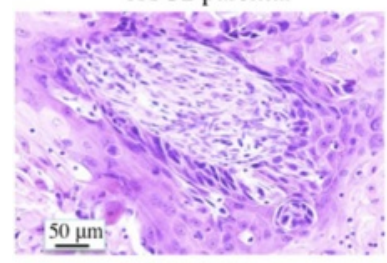

$\mathrm{HSC} 2 / \mathrm{hSK}$

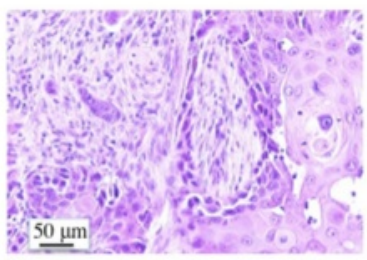

HSC2/hOCT3/4-shp53-F+hUL

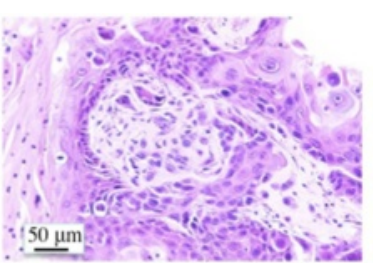

HSC2/EGFP

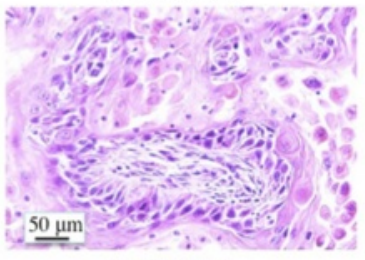

$\mathrm{HSC} 2 / \mathrm{hUL}$

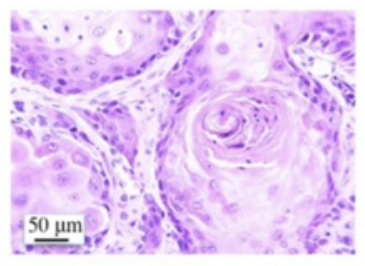

HSC $2 / \mathrm{hSK}+\mathrm{hUL}$

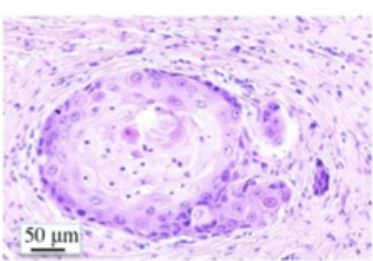

HSC2/hOCT3/4-shp53-F

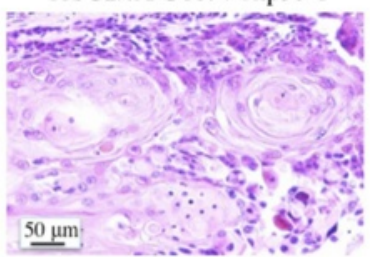

HSC2/hOCT3/4-shp53-F+hSK

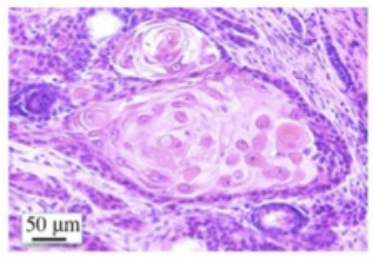

HSC2/hOCT3/4-shp53-F+hSK+hUL

Fig. 9 Histological analysis of nude mice tumors. HSC2 or HSC2/EGFP $\left(5 \times 10^{6}\right)$ were inoculated into BALB/C nude mice subcutaneously to make each tumor mass. Each tumor was dissected out, fixed in neutral-buffered formalin, embedded in paraffin and stained with hematoxylin and eosin. Histological analysis of these tumors showed squamous cell carcinoma tissues including from highly to poorly differentiated areas, but teratomas were not observed $(B a r=50 \mu \mathrm{m})$ 


\section{Conclusion}

In summary, we here describe the possibility of reprogramming non-CSCs by the introduction of defined reprogramming factors and the consequent generation of artificial CSCs. These findings may provide a valuable model system for the study of CSCs, which might help in the development of new therapeutic strategies targeting CSCs in oral tumors.

\begin{abstract}
Abbreviations
5-FU, 5-fluorouracil; ABC transporters, ATP-binding cassette transporters; CDDP, cisplatin; CiRA, center for iPS cell research and application; CSC, cancer stem cell; D-MEM, Dulbecco's modified Eagle's medium; DOC, docetaxel; EGF, epidermal growth factor; FBS, fetal bovine serum; FGF-2, fibroblast growth factor-2; HNSCC, head and neck squamous cell carcinoma; IgG, immunoglobulin G; iPSC, induced pluripotent stem cell; MTT, 3-(4, 5-dimethylthiazol- 2-yl)-2, 5- diphenyltetrazolium bromide; NSC, neural stem cell; OD: optical density; OSCC, oral squamous cell carcinoma; RIPA, radioimmunoprecipitation assay; TFT, trifluorothymidine

\section{Acknowledgements}

Not applicable.

\section{Funding}

This study was supported in part by a Grant-in-Aid from the Japanese Ministry of Education, Science and Culture (Grant no. 24593034).
\end{abstract}

\section{Availability of data and materials}

We state that we agree to share these data. The datasets supporting the conclusions of this article are included within the article.

\section{Authors' contributions}

$\mathrm{KH}$ was involved in the study design, data analysis, and writing of the manuscript. TF carried out the experiments, data collection and evaluation, and assisted in manuscript writing. DC helped in data analysis. TM and El evaluated some data. $\mathrm{YK}$ and $\mathrm{HO}$ helped in writing the manuscript. $\mathrm{HO}$ and YU revised and edited the manuscript. All the authors read and approved the final version of the manuscript.

\section{Competing interests}

$\mathrm{HO}$ is a paid member of the scientific advisory board of San Bio Co., Ltd. Other authors declare that they have no competing interests.

\section{Consent for publication}

Not applicable.

\section{Ethics approval and consent to participate}

All in vivo studies and experiments were approved by the Institutional Animal Care and Use Committee of Yamaguchi University (Ube, Japan).

\section{Author details}

${ }^{1}$ Department of Oral and Maxillofacial Surgery, Yamaguchi University Graduate School of Medicine, 1-1-1, Minamikogushi, Ube 755-8505, Japan. ${ }^{2}$ Department of Pathology, Yamaguchi University Graduate School of Medicine, 1-1-1, Minamikogushi, Ube 755-8505, Japan. ${ }^{3}$ Department of Biochemistry and Functional Proteomics, Yamaguchi University Graduate School of Medicine, 1-1-1, Minamikogushi, Ube 755-8505, Japan. ${ }^{4}$ Department of Physiology, Keio University, School of Medicine, 35 Shinanomachi, Shinjuku-ku, Tokyo 160-8582, Japan.

Received: 13 November 2015 Accepted: 15 June 2016 Published online: 27 July 2016

\section{References}

1. Mannelli G, Gallo O. Cancer stem cells hypothesis and stem cells in head and neck cancers. Cancer Treat Rev. 2012;38:515-39.

2. Zhang Z, Filho MS, Nör JE. The biology of head and neck cancer stem cells. Oral Oncol. 2012;48:1-9.
3. Chiou SH, Yu CC, Huang CY, Lin SC, Liu CJ, Tsai TH, Chou SH, Chien CS, Ku $\mathrm{HH}$, Lo JF. Positive correlations of Oct-4 and Nanog in oral cancer stem-like cells and high-grade oral squamous cell carcinoma. Clin Cancer Res. 2008;14:4085-95.

4. Visvader JE, Lindeman GJ. Cancer stem cells in solid tumours: accumulating evidence and unresolved questions. Nat Rev Cancer. 2008:8:755-68.

5. Al-Hajj M, Wicha MS, Benito-Hernandez A, Morrison SJ, Clarke MF. Prospective identification of tumorigenic breast cancer cells. Proc Natl Acad Sci U S A. 2003;100:3983-8.

6. Singh SK, Clarke ID, Terasaki M, Bonn VE, Hawkins C, Squire J, Dirks PB. Identification of a cancer stem cell in human brain tumors. Cancer Res. 2003;63:5821-8.

7. Ramdass B, Chowdhari A, Koka P. Cancer-initiating cells as target for prevention of recurring disease etiology: role of these malignant putative progenitor cells in relapse or metastasis of human cervical carcinoma. J Stem Cells. 2013;8:233-51. Review.

8. Dean M, Fojo T, Bates S. Tumour stem cells and drug resistance. Nat Rev Cancer. 2005;5:275-84. Review.

9. Yu Z, Pestell TG, Lisanti MP, Pestell RG. Cancer stem cells. Int J Biochem Cell Biol. 2012;44:2144-51.

10. Krause M, Yaromina A, Eicheler W, Koch U, Baumann M. Cancer stem cells: targets and potential biomarkers for radiotherapy. Clin Cancer Res. 2011;17:7224-9.

11. Nishi M, Akutsu H, Kudoh A, Kimura H, Yamamoto N, Umezawa A, Lee SW, Ryo A. Induced cancer stem-like cells as a model for biological screening and discovery of agents targeting phenotypic traits of cancer stem cell. Oncotarget. 2014:5:8665-80.

12. Tirino $V$, Desiderio $V$, Paino F, De Rosa A, Papaccio F, La Noce M, Laino L, De Francesco F, Papaccio G. Cancer stem cells in solid tumors: an overview and new approaches for their isolation and characterization. FASEB J. 2013;27:13-24

13. Moghbeli M, Moghbeli F, Forghanifard MM, Abbaszadegan MR. Cancer stem cell detection and isolation. Med Oncol. 2014;31:69.

14. Shimamura M, Nagayama Y, Matsuse M, Yamashita S, Mitsutake N. Analysis of multiple markers for cancer stem-like cells in human thyroid carcinoma cell lines. Endocr J. 2014:61:481-90.

15. Yan M, Yang X, Wang L, Clark D, Zuo H, Ye D, Chen W, Zhang P. Plasma membrane proteomics of tumor spheres identify CD166 as a novel marker for cancer stem-like cells in head and neck squamous cell carcinoma. Mol Cell Proteomics. 2013;12:3271-84

16. Athanassiou-Papaefthymiou M, Shkeir O, Kim D, Divi V, Matossian M, Owen $J$ H, Czerwinski MJ, Papagerakis P, McHugh J, Bradford CR, Carey TE, Wolf GT, Prince ME, Papagerakis S. Evaluation of CD44 variant expression in oral, head and neck squamous cell carcinomas using a triple approach and its clinical significance. Int J Immunopathol Pharmacol. 2014;27:337-49.

17. Shrivastava S, Steele R, Sowadski M, Crawford SE, Varvares M, Ray RB. Identification of molecular signature of head and neck cancer stem-like cells. Sci Rep. 2015;5:7819.

18. Bhaijee F, Pepper DJ, Pitman KT, Bell D. Cancer stem cells in head and neck squamous cell carcinoma: a review of current knowledge and future applications. Head Neck. 2012:34:894-9.

19. Ji J, Wang XW. Clinical implications of cancer stem cell biology in hepatocellular carcinoma. Semin Oncol. 2012;39:461-72.

20. Tabor MH, Clay MR, Owen JH, Bradford CR, Carey TE, Wolf GT, Prince ME. Head and neck cancer stem cells: the side population. Laryngoscope. 2011;121:527-33.

21. Richard V, Nair MG, Santhosh Kumar TR, Pillai MR. Side population cells as prototype of chemoresistant, tumor-initiating cells. Biomed Res Int. 2013;2013:517237

22. O'Brien CA, Kreso A, Jamieson CH. Cancer stem cells and self-renewal. Clin Cancer Res. 2010;16:3113-20. Review.

23. Reya T, Morrison SJ, Clarke MF, Weissman IL. Stem cells, cancer, and cancer stem cells. Nature. 2001;414:105-11

24. Tang DG. Understanding cancer stem cell heterogeneity and plasticity. Cell Res. 2012;22:457-72

25. Marjanovic ND, Weinberg RA, Chaffer CL. Cell plasticity and heterogeneity in cancer. Clin Chem. 2013;59:168-79.

26. Bao B, Ahmad A, Azmi AS, Ali S, Sarkar FH. Overview of cancer stem cells (CSCs) and mechanisms of their regulation: implications for cancer therapy. Curr Protoc Pharmacol. 2013, Chapter 14: Unit 14.25. doi: 10.1002/ 0471141755.ph1425s61. 
27. Tsai LL, Hu FW, Lee SS, Yu CH, Yu CC, Chang YC. Oct4 mediates tumor initiating properties in oral squamous cell carcinomas through the regulation of epithelial-mesenchymal transition. PLoS One. 2014;9, e87207.

28. Qiao B, He B, Cai J, Yang W. The expression profile of Oct4 and Sox2 in the carcinogenesis of oral mucosa. Int J Clin Exp Pathol. 2013;7:28-37.

29. Wang J, Wang H, Li Z, Wu Q, Lathia JD, McLendon RE, Hjelmeland AB, Rich JN. c-Myc is required for maintenance of glioma cancer stem cells. PLoS One. 2008;3, e3769.

30. Yu F, Li J, Chen H, Fu J, Ray S, Huang S, Zheng H, Ai W. Kruppel-like factor 4 (KLF4) is required for maintenance of breast cancer stem cells and for cell migration and invasion. Oncogene. 2011;30:2161-72.

31. Takahashi K, Yamanaka S. Induction of pluripotent stem cells from mouse embryonic and adult fibroblast cultures by defined factors. Cell. 2006;126:663-76

32. Takahashi K, Tanabe K, Ohnuki M, Narita M, Ichisaka T, Tomoda K, Yamanaka S. Induction of pluripotent stem cells from adult human fibroblasts by defined factors. Cell. 2007;131:861-72.

33. Okita K, Yamakawa T, Matsumura Y, Sato Y, Amano N, Watanabe A, Goshima $\mathrm{N}$, Yamanaka S. An efficient nonviral method to generate integration-free human-induced pluripotent stem cells from cord blood and peripheral blood cells. Stem Cells. 2013;31:458-66.

34. Okita K, Matsumura Y, Sato Y, Okada A, Morizane A, Okamoto S, Hong H, Nakagawa M, Tanabe K, Tezuka K, Shibata T, Kunisada T, Takahashi M, Takahashi J, Saji H, Yamanaka S. A more efficient method to generate integration-free human iPS cells. Nat Methods. 2011;8:409-12.

35. Ben-Porath I, Thomson MW, Carey VJ, Ge R, Bell GW, Regev A, Weinberg, R. A. An embryonic stem cell-like gene expression signature in poorly differentiated aggressive human tumors. Nat Genet. 2008;40:499-507.

36. Okano H, Nakamura M, Yoshida K, Okada Y, Tsuji O, Nori S, Ikeda E, Yamanaka S, Miura K. Step toward safe cell therapy using induced pluripotent stem cell. Circ Res. 2013;112:523-33. Review.

37. Ohnishi K, Semi K, Yamamoto T, Shimizu M, Tanaka A, Mitsunaga K, Okita K, Osafune K, Arioka Y, Maeda T, Soejima H, Moriwaki H, Yamanaka S, Woltjen K, Yamada Y. Premature termination of reprogramming in vivo leads to cancer development through altered epigenetic regulation. Cell. 2014;156:663-77.

38. Matsui T, Takano M, Yoshida K, Ono S, Fujisaki C, Matsuzaki Y, Toyama Y, Nakamura M, Okano H, Akamatsu W. Neural stem cells directly differentiated from partially reprogrammed fibroblasts rapidly acquire gliogenic competency. Stem Cells. 2012;30:1109-19.

39. Kim J, Efe JA, Zhu S, Talantova M, Yuan X, Wang S, Lipton SA, Zhang K, Ding S. Direct reprogramming of mouse fibroblasts to neural progenitors. Proc Natl Acad Sci U S A. 2011;108:7838-43.

40. Wang T, Choi E, Monaco MC, Major EO, Medynets M, Nath A. Direct induction of human neural stem cells from peripheral blood hematopoietic progenitor cells. J Vis Exp. 2015;95:52298.

41. Szabo E, Rampalli S, Risueño RM, Schnerch A, Mitchell R, Fiebig-Comyn A, Levadoux-Martin M, Bhatia M. Direct conversion of human fibroblasts to multilineage blood progenitors. Nature. 2010;468:521-6.

42. Protocol for iPS cell generation using episomal vectors. Website: http:// www.cira.kyoto-u.ac.jp/j/research/img/protocol/Episomal_Protocol.pdf. Japanese, Date of access: 13th Aug 2014.

43. Muto J, Imai T, Ogawa D, Nishimoto Y, Okada Y, Mabuchi $Y$, Kawase T, Iwanami A, Mischel PS, Saya H, Yoshida K, Matsuzaki Y, Okano H. RNAbinding protein Musashi1 modulates glioma cell growth through the posttranscriptional regulation of Notch and PI3 kinase/Akt signaling pathways. PLoS One. 2012;7, e33431.

44. Nishi M, Sakai Y, Akutsu H, Nagashima Y, Quinn G, Masui S, Kimura H, Perrem K, Umezawa A, Yamamoto N, Lee SW, Ryo A. Induction of cells with cancer stem cell properties from nontumorigenic human mammary epithelial cells by defined reprogramming factors. Oncogene. 2014;33:643-52.

45. Miyoshi N, Ishii H, Nagai K, Hoshino H, Mimori K, Tanaka F, Nagano H, Sekimoto M, Doki Y, Mori M. Defined factors induced reprogramming of gastrointestinal cancer cells. Proc Natl Acad Sci U S A. 2010;107:40-5.

46. Oshima N, Yamada Y, Nagayama S, Kawada K, Hasegawa S, Okabe H, Sakai $Y$, Aoi T. Induction of cancer stem cell properties in colon cancer cells by defined factors. PLoS One. 2014;9, e101735.

47. Carette JE, Pruszak J, Varadarajan M, Blomen VA, Gokhale S, Camargo FD, Wernig M, Jaenisch R, Brummelkamp TR. Generation of iPSCs from cultured human malignant cells. Blood. 2010;115:4039-42.
48. Utikal J, Maherali N, Kulalert W, Hochedlinger K. Sox2 is dispensable for the reprogramming of melanocytes and melanoma cells into induced pluripotent stem cells. J Cell Sci. 2009;122:3502-10.

49. Ciurea ME, Georgescu AM, Purcaru SO, Artene SA, Emami GH, Boldeanu MV, Tache DE, Dricu A. Cancer stem cells: biological functions and therapeutically targeting. Int J Mol Sci. 2014;15:8169-85.

50. Alisi A, Cho WC, Locatelli F, Fruci D. Multidrug resistance and cancer stem cells in neuroblastoma and hepatoblastoma. Int J Mol Sci. 2013;14:24706-25.

51. Padmanabhan R, Chen KG, Gillet JP, Handley M, Mallon BS, Hamilton RS, Park K, Varma S, Mehaffey MG, Robey PG, McKay RD, Gottesman MM. Regulation and expression of the ATP-binding cassette transporter ABCG2 in human embryonic stem cells. Stem Cells. 2012;30:2175-87.

\section{Submit your next manuscript to BioMed Central and we will help you at every step:}

- We accept pre-submission inquiries

- Our selector tool helps you to find the most relevant journal

- We provide round the clock customer support

- Convenient online submission

- Thorough peer review

- Inclusion in PubMed and all major indexing services

- Maximum visibility for your research

Submit your manuscript at www.biomedcentral.com/submit
C Biomed Central 